\title{
Fully Non-linear Numerical Simulation of a Shaking Table Test of Dynamic Soil-Pile- Structure Interactions in Soft Clay using ABAQUS
}

\author{
Al-Isawi A.T., ${ }^{1}$ Collins P.E.F. ${ }^{2}$ and Cashell K.A. ${ }^{3}$ \\ ${ }^{1}$ Department of Civil and Environmental Engineering, \\ Brunel University London; e-mail: Alaa.Al-Isawi@brunel.ac.uk \\ ${ }^{2}$ Vice Dean Education/Senior Lecturer, Department of Civil and Environmental Engineering, \\ Brunel University London; e-mail: Philip.Collins@brunel.ac.uk \\ ${ }^{3}$ Senior Lecturer, Department of Civil and Environmental Engineering, \\ Brunel University London; e-mail: Katherine.Cashell@brunel.ac.uk
}

\section{Abstract}

There are a significant number of studies into the failure of pile-supported structures exposed to earthquakes, however, there remain a difficulties with the in situ examination of pile response and performance during seismic excitation. A flexible wall barrel, shaking table test method is suitable for investigating pile behavior during an earthquake. Cost, time and difficulties in identifying soil properties accurately in physical models, in addition to the effects of test conditions, have led to the current research where the physical test is replaced by numerical simulation. Many researchers have experienced difficulties in the validation of numerical models and have found that there is a lack of available information in the literature. Thus, developing a practical approach will extend the soil-structure interaction (SSI) database and promote the validation opportunities for studies into pile performance during strong excitations. This study provides an insight into a set of SSI problems and proposes a procedure for calibration of the advanced SSI analysis. A framework is performed to simulate a shaking table test of a model pile-foundation superstructure on soft clay. A variety of model scaling relationships are used to develop an approach that allows observation of the inherent dynamic and non-linear nature of SSI behavior. The three-dimensional, non-linear dynamic response and elastoplastic analysis are included in the simulation. Through the development of finite element analysis (FEA) using ABAQUS software, fully non-linear unidirectional input excitations, which are amplified from the base to the top and are capable of including all of the possible degrees of freedom, are applied to the model. The inertial, kinematic and damping interaction components of the response are also examined. The gap-slap mechanism between soil and pile is a significant aspect to the model. The results are validated using physical test results.

\subsection{Introduction}

Deep foundations are typically used in the design of structures which are on built on relatively soft soils in order to ensure that the axial loads are successfully transferred and so that the deeper strata are strengthened in their load-bearing capacity. Cyclical lateral and transient loads often affect these foundation elements; these can arise from waves, blasts, impacts, machine loading, and other natural disasters such as earthquakes. These deep foundations are subjected to significant demands, mainly if they are situated in zones with soft soils together with a substantial number of pile-supported structures. Potential resonance repercussions between the longer period soft soil locations, which is something that increases and amplifies the ground movement, and high structures may intensify the problem. Within these soft soils, the potential for strain softening and/or liquefaction may add to the demand on pile foundation systems.

Traditionally, the impact of soil-structure interaction (SSI) has been routinely considered in seismic design practices. A spectral analysis approach is usually adopted which results in its conservative design owing to the inherent simplifications. This is because a period of increased dampening and lengthening - resulting from flexible pile foundations-manifests and results in structural forces being decreased when contrasted and compared to fixed-base examples. 
Nevertheless, some special cases exist, such as the 1985 Mexico City earthquake wherein period lengthening meant that spectral values were increased when compared to existing code specifications at the time. The stiffness of the pile foundation system can be decreased by including the effects of SSI, which is also accountable for increased permanent deformations; thus, the displacement and seismic response of the structure as a whole can be impacted. Highrise buildings may be subjected to resonance as a result of SSI during an earthquake event (Guin \& Banerjee, 1998; Phanikanth1et al., 2015; Mylonakis \& Gazetas, 2000; Malhotra, 2010). There are two main aspects relating to pile performance that must be considered during an earthquake. Firstly, ground motions that are experienced by the superstructure are impacted by the pile foundations and, secondly, extreme damage and even failure can occur to the piles during an earthquake due to seismic loading. Furthermore, numerous phenomena emerge from seismic soil-pile-superstructure interactions (SSPSI) which are complicated in nature and bring about ground deformation, the creation of pore pressure as well as a so-called gap-slap mechanism (see section 4.3). Physical shaking tests allow for the assessment and examination of the aforementioned aspects, but multifaceted soil-structure interaction modeling through numerical analysis also facilitates the same goal.

A lack of information available in the literature concerning seismic soil-pile and response case histories means that the phenomenon is not well documented. Only a small number of the existing case studies include piles that record dynamic reactions and responses using instrumented measurements. Pile performance under earthquake conditions currently has no sound validation or calibration methods or guidelines due to the limited databases available. Indeed, the current limitations in the SSPSI database can be solved or mitigated by adopting numerical methods; as a result, field case histories can be validated with the use of shaking table model tests. However, physical shaking table tests for clay are expensive regarding cost, facilities and time. Furthermore, it is complicated to capture the site's specific soil properties for the soil specimen in the laboratory. Therefore, utilizing validated numerical analysis to understand the behavior further can overcome some of these issues. In the current paper, ABAQUS software has been used to develop a 3D, non-linear FEA model with a gap-slap mechanism so that a simulation of a flexible wall barrel shaking table test can be undertaken. The model is validated using available physical test data (Meymand, 1998).

\subsection{The characteristics of seismic soil-structure interaction}

The primary characteristics of SSPSI can be seen in Figure 1. The pile(s), the pile cap, the superstructure, the near- and far-field domains of the soil, and the energy source of the seismic activity are all systemic components of this arrangement. Kinematic, inertial, radiation damping, and physical interaction modes are featured in the system. The kinematic formula for interaction analysis of the pile-soil-structure system can be given as:

$M \ddot{u}(t)+D \dot{u}(t)+K u(t)=P(t)$

Here, the node acceleration is $\ddot{u}(t)$, the velocity of the node $\dot{u}(t)$, the displacement of the node $u(t)$ and $\mathrm{M}, \mathrm{D}, \mathrm{K}$ and $P(t)$ refer to the mass matrix, the damping matrix, the stiffness matrix and the load vector of the node of the system, respectively. The complexity of SSPSI is shown by the high degree of system coupling between the system components and the interaction modes; another level of complexity can be added by the seismic response of piles installed in a group system. In systems that have a robust non-linear response, a fully coupled analysis approach may be preferable. Such an analysis technique can evaluate how the development of non-linearity in one component of the system affects the demands on another, which may potentially contribute to more reliable and economical design practice. This is in contrast to the commonly used, so-called dynamic sub-structuring methods. 


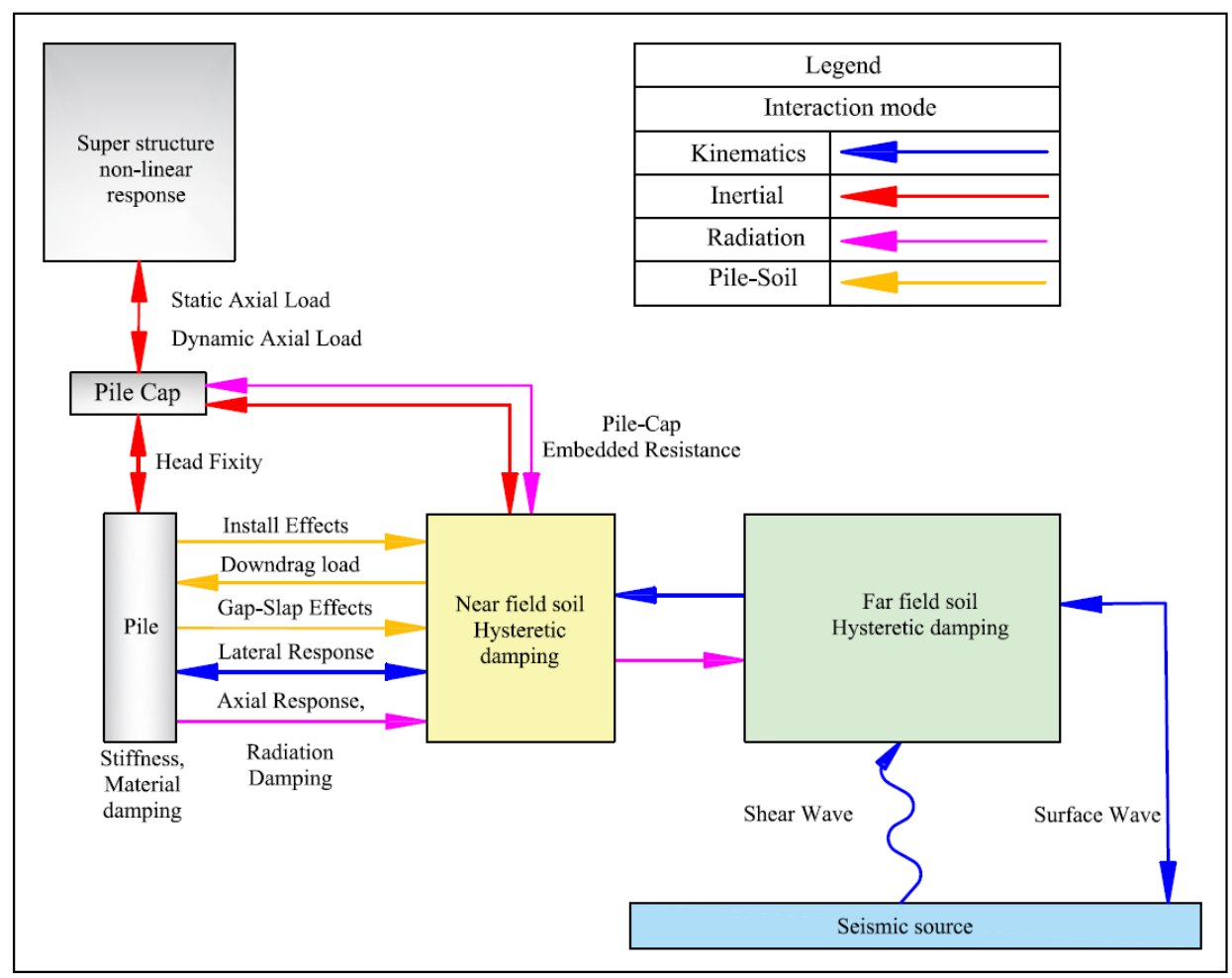

Figure 1. Single Pile Seismic Response Modes (based on Meymand, (1998))

\subsection{Scale model criteria}

It is possible to simulate complicated and multifaceted systems within a set of controlled variables and conditions using scale models. Scale modeling allows the user to better understand the relationship between the corresponding behavior of a prototype and the scale model itself. There are three different approaches by which the power and complexity of scale model applications can be realized (Kline, 1986). These three methods are similitude theory, dimensional analysis and the method used for the governing equations. Meymand (1998) also provided a composite and original procedure so that the physical shaking table test and the model part could be scaled based on these scaling relations expressed in terms of the geometric scale factor $(\lambda)$ of the primary system variables, Table 1. Meymand (1998) scaling procedure has been adopted in this study. This method will be targeted as part of the validation of the numerical simulations within this study.

Table 1. Geometric scaling factor $\lambda$ (Meymand, 1998)

\begin{tabular}{|l|c|l|c|}
\hline \multicolumn{1}{|c|}{ Variable } & Factor & \multicolumn{1}{c|}{ Variable } & Factor \\
\hline Mass Density & \multirow{3}{*}{1} & Force & $\lambda^{3}$ \\
\cline { 4 - 4 } Acceleration & EI & $\lambda^{5}$ \\
\cline { 1 - 1 } Strain & \multirow{2}{*}{$\lambda$} & Frequency & $\lambda^{-\frac{1}{2}}$ \\
\cline { 3 - 4 } Length & Stiffness & $\lambda^{2}$ \\
\cline { 3 - 4 } Stress & Time & $\lambda^{\frac{1}{2}}$ \\
\hline
\end{tabular}

\subsubsection{Definition of prototype soil parameters}

San Francisco Bay mud, as used by Meymand (1998), was also chosen as the target prototype soil for the research herein. In 1994 Dickenson examined the seismic response of the Bay mud during the 1989 earthquake in Loma Prieta, and suggested a relationship between the shear wave velocity $V_{s}$ and the undrained shear strength $\left(S_{u}\right)$, (Badrakia, 2016), as follows:

$$
V_{s}=18\left(S_{u}\right)^{0.475}
$$


In this expression, $S_{u}$ is shown in pounds per square foot, and $V_{s}$ is shown in feet per second. The aforementioned formula determines the target shear wave velocities for the soil used in the prototype. Imperial System (IS) units should be used for the calculation, and therefore any SI units must be converted. The undrained shear strengths used by Meymand (1998) for the prototype soil varied from $28.7 \mathrm{kN} / \mathrm{m}^{2}$ as a minimum and $57.5 \mathrm{kN} / \mathrm{m}^{2}$ as a maximum value; 114.3 to $160 \mathrm{~m} / \mathrm{s}$ was the range computed for the shear wave velocities. As a result of the impact of thixotropy of the soil and the advantages thereof, a five-day interval was allowed before the next test was conducted so that the model could subsequently reconsolidate. The desired soil with the correct constitution and characteristics was achieved by adding fly ash. The shear wave velocity value of the soil-fly ash mix was $30.5 \mathrm{~m} / \mathrm{s}$; the reference case does not provide all of the model soil parameters, so some of them were either computed or assumed depending on the information provided by Meymand (1998). An adequate scale model was set up according to the higher-plasticity to medium-stiff clays, which are comparable to San Francisco Bay mud.

\subsubsection{Model pile design}

The pile used as the model was subjected to realistic scale modeling criteria. A successful model pile design was realized through addressing those main and primary governing pile response factors as can be seen in Figure 1. The four main pile response modes are pile radiation damping, soil-pile axial response, soil-pile lateral kinematic interaction and soil-pile lateral inertial interaction. Several properties of the pile have been highlighted as a result, including buckling properties $\left(P_{c r}\right)$ and the $(\mathrm{d} / \mathrm{t})$ ratio, where $\mathrm{d}$ is the diameter of the pile and $\mathrm{t}$ the thickness of the pile's wall; relative soil/pile stiffness; the yield behaviour/mechanism; the slenderness ratio (L/d), where (L) is the length of the pile; flexural rigidity (EI), where (E) is Young's modulus and (I) is the second moment of area; the natural period of vibration (T); and the moment-curvature relationship. Strict modeling constraints demanded the use of geometric similarity, and therefore relative contact surface area and overall pile slenderness are retained in the model. By appropriately scaling the (closed end condition pile) the pile elastic properties and the soil properties, the stiffness of the relative soil pile is scaled automatically from the model to the prototype. According to Clough and Penzien (2015), the correct description of the vibration frequency for a cantilever rod can help to idealize the vibration frequency of an endbearing pile; this is seen below in the form of a function of the mass of the rod (M).

$$
\omega=3.516 \sqrt{\frac{\mathrm{EI}}{\mathrm{ML} L^{4}}}
$$

With correct scaling (as above) of the pile geometry and EI, the pile's mass per unit length needs to be scaled according to a $\lambda^{2}$ factor from the initial prototype. Both shift and bearing pile resistance is considered see section (4.0). Four pile head masses equivalent to $72.60 \mathrm{~kg}$, $45.36 \mathrm{~kg}, 11.35 \mathrm{~kg}$, and $3.0 \mathrm{~kg}$, respectively, have been adopted as superstructures.

\subsection{Test program for the shaking table test [transformation]}

A more realistic response is obtained from the flexible wall barrel test compared to alternative containers (Meymand, 1998). When the seismic waves move and propagate to the top of the container from the bottom, the container permits the soil to travel and shake in a horizontal direction along the depth. The shaking table test program is essential for two reasons: initially, such tests are intended to provide, in a qualitative fashion, some information about the various SSPSI problems; and secondly, the tests were operated with the intent of creating a calibration data set. This work will transfer Meymand's physical test to a fully numerical test; this paper, therefore, represents a first step towards developing a full numerical framework of a shaking table test and will thereby permit the calibration and validation of soil-structural interaction issues. This allows the examination of inertial and kinematic interaction for single piles, and 
validation of the results with physical results, as attained herein. The following dimensions from the physical test are considered in the numerical model: height of the wall $\left(h_{\text {wall }}\right)=$ $2082.8 \mathrm{~mm}$, which contained a column of soil with a diameter $\left(d_{\text {soil }}\right)$ of $2286.0 \mathrm{~mm}$ and a height $\left(h_{\text {soil }}\right)$ of $1828.8 \mathrm{~mm}$. The wall comprised a $6.35 \mathrm{~mm}$ thick rubber membrane, confined using Kevlar straps which were $50.8 \mathrm{~mm}$ wide and $1.83 \mathrm{~mm}$ thick; these were arranged about the membrane's exterior with $101.6 \mathrm{~mm}$ center-to-center sets. The Kevlar bands and the rubber membrane in combination provided the preferred container characteristics and properties regarding related stiffness and lateral flexibility. A path for complementary shear stress was created by this combination, which allowed shear stresses in the soil to be transferred within the container. The piles were driven into the soil, for every one of the test series, before the test took place. The piles were then removed and soil was poured into the holes. As a result of the soil's thixotropic beneficial impact, the model was left to stand for five days prior to the next scheduled test.

\subsection{The input motions}

Three levels of excitation were chosen for the physical soil-pile scale model tests. A low sine sweep signal with an acceleration level of $=0.05 \mathrm{~g}$ was targeted to ensure that response remained in the elastic range. A mid-range signal with a PGA (Peak Ground Acceleration) of about $0.2 \mathrm{~g}$ was aimed to transmit an intermediate level excitation. Finally, a strong excitation record with a PGA $=0.7 \mathrm{~g}$ was desired to typical of design level events in regions of high seismicity. The mid-range of $0.20 \mathrm{~g}$ was employed in this study. Motion on the bedrock was accounted for, as the model site profile was representative of soft clay which lay over a thick, stiff soil layer above bedrock strata. The signal input criterion for the test was motion recorded on the bedrock; for the numerical model, this was the base of the shacking table in the analysis. The database in PEER Ground Motion Database - PEER Center website was used ((PEER), 2008), and the actual earthquake data utilized in the model was the same as that used in the physical test. The Yerba Buena Island (90 degrees) component (YBI90) taken from the Loma Prieta earthquake was used. The YBI90 was seen to have a predominant frequency of $1.5 \mathrm{~Hz}$, as well as a PGA of $0.07 \mathrm{~g}$; this was scaled to $0.20 \mathrm{~g}$ for this testing stage, with a time step of $0.02 \mathrm{~s}$. The time steps of this record were then divided by $\lambda^{0.5}$. Unidirectional shaking employed these solitary component input motions.

\subsection{Finite element model mesh and boundary condition}

According to (Bezgin, (2010)), meshing in the SSI model is very influential and must be appropriately implemented. Herein, the most significant and relevant mesh to be used for the SSI model is a radial mesh; mesh quality is also an essential factor. Standard, solid, 3D stress, and linear element types (C3D8R in the ABAQUS library, which is an 8-node linear brick element with reduced integration) are used to simulate the soil deposit and superstructure. Standard, linear, and shell element types (S4R in the ABAQUS library, which is a 4-node doubly curved shell element with reduced integration and finite membrane strains) are used to simulate the flexible wall and pile. The ring element is simulated as a rigid body, as previously mentioned. Within this study, the boundary conditions are equivalent to those of the flexible wall barrier physical test. At the top of all the rubber membranes and the confining rings, displacements are not allowed in the vertical direction, and free movement is only permitted in the horizontal direction. Ties were made between the rubber membranes and the rigid confining rings to achieve a combined behavior of these two parts to ensure they behaved as one unit. Simulating these rubber membranes and the confining rings with these particular constraints and boundary conditions assists the soil in retaining its geometrical properties and shape. Roller support is used to constrain the displacement vertically at the bottom of the model. The horizontal boundary conditions permit "Free" shaking in the direction of the applied seismic 
load; the second direction is constrained for this unidirectional test case. Figure 2 shows the mesh and model geometry.

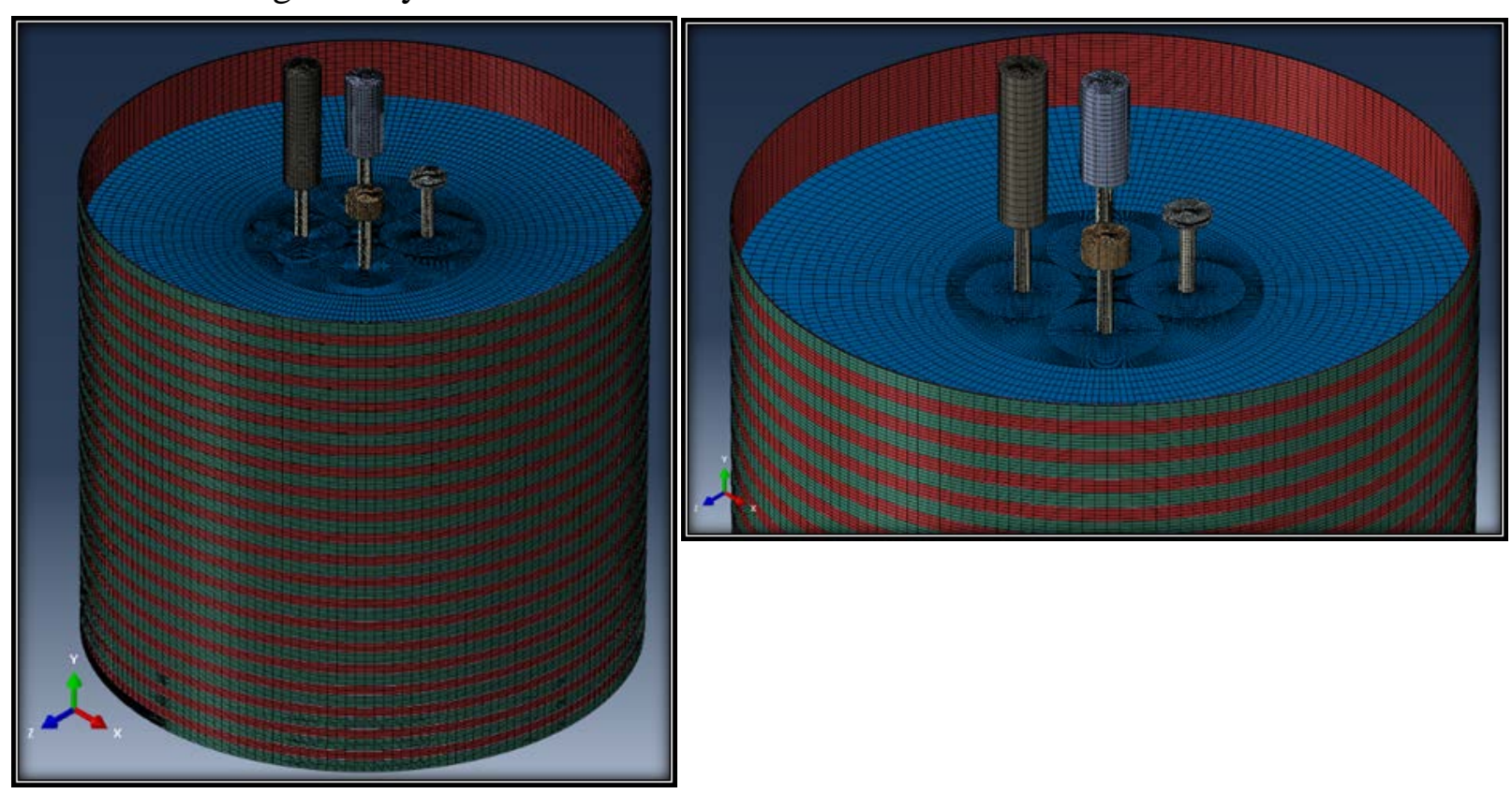

Figure 2. The mesh and the model geometry

\subsection{Soil constitutive models and parameters}

The Mohr-Coulomb theory is a mathematical model defining the response of a material to shear stress and normal stress. In geotechnical engineering, the Mohr-Coulomb criterion is used to describe soil shear strength at different values of effective stress. Equation 4 presents the MohrCoulomb soil pressure theory in the $\tau, \sigma$ plane as:

$$
\tau=c+\sigma \tan \varnothing
$$

In this expression, $\tau$ and $\sigma$ are the shear strength and normal stress upon the shearing surface, respectively; the cohesion and the angle of internal friction in the soil are shown, respectively, as c and $\varnothing$. Mohr devised a Coulomb failure condition within the shear failure law, named the Mohr-Coulomb yield criterion, and this may be expanded upon and stated according to the principle stresses within the experiment $\left(\sigma_{1} \geq \sigma_{2} \geq \sigma_{3}\right)$ as I equation 5:

$$
F=\left(\sigma_{1}-\sigma_{3}\right)+\left(\sigma_{1}+\sigma_{3}\right) \sin \emptyset-2 c \cos \emptyset=0
$$

The Extended Mohr-Coulomb (EMC) elastoplastic model was developed by Muir Wood( 2004) for triaxial stress conditions. The yielding surface, flow rule, and a hardening law in EMC are considered to be similar to the general Mohr-Coulomb criterion (Leoni, 2005). Equations 6 and 7 present the failure surface in EMC:

$$
F=R_{m c}(\theta, \varnothing) q-p \tan \varphi-C=0
$$

and;

$$
R_{m c}(\theta, \varnothing)=\frac{1}{\sqrt{3} \cos \emptyset} \sin \left\{\theta+\frac{\pi}{3}\right\}+\frac{1}{3} \cos \left\{\theta+\frac{\pi}{3}\right\} \tan \emptyset
$$

Where $\theta$ the deviatoric polar angle, $\phi$ is the slope of the failure line in the $p / R_{m c} . q$ plane, and $C$ (represented by $S_{u}$ in this study) the soil cohesion (Chen \& Zhang , 1988). The stress deviator and effective mean stress are shown as $q$ and $p$, respectively; see Figure 3.The plastic flow potential on the Mohr-Coulomb yield surface is shown in Figure 3, and the plastic potential 
equation is defined by Menetrey and Willam, (1995) as a smooth elliptic function, equation 8:

$$
G=\sqrt{\left(\varepsilon C_{\left.\right|_{0}} \tan \varphi\right)^{2}+\left(R_{m w} q\right)^{2}}-p \tan \Psi
$$

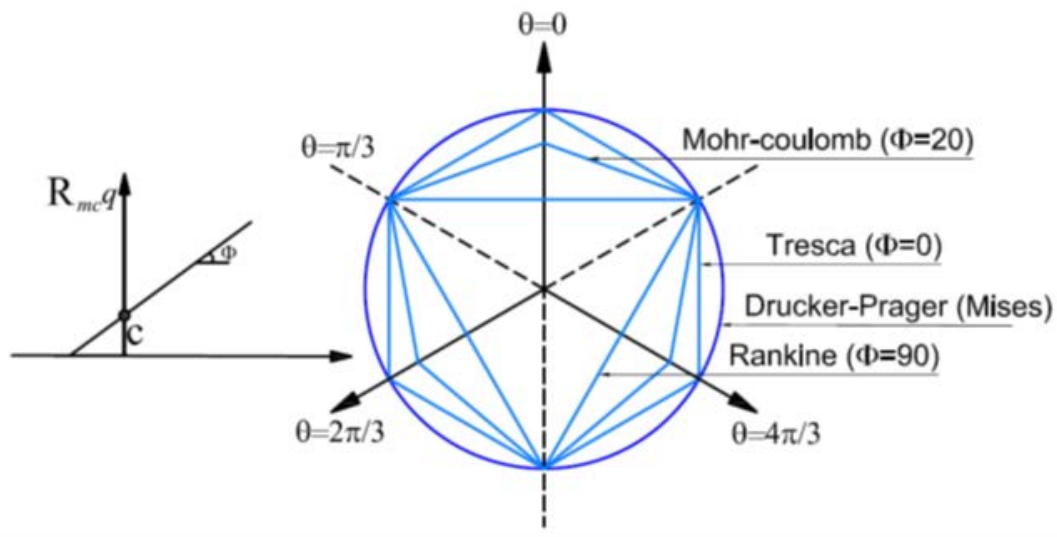

Figure 3. Mohr-Coulomb yield surface in meridional and deviatoric planes (ABAQUS)

where $G$ is the plastic flow potential for the Mohr-Coulomb yield surface; $R_{m w}$ is a function of Lode's angle; $\Psi$ is the dilatancy angle; $C_{\left.\right|_{0}}$ is the initial cohesion yield stress; and $\varepsilon$ is the eccentricity, which represents the rate at which the function meets the asymptote. The flow potential, which is continuous and smooth in the meridional stress plane tends to be a straight line as the eccentricity tends to zero (ABAQUS, 2016), and it is ensured that the direction of the flow is precisely defined in this plane. In conclusion, in order to use EMC model in ABAQUS software, seven parameters have to be provided as main parameters which are: the angle of internal friction, $\emptyset=20^{\circ}$, the dilatancy angle, $\Psi=20^{\circ}$, Undrained shear strength, $S_{\mathrm{u}}=4.6$ $\mathrm{kPa}$, Modulus of elasticity, $E_{s}=4200 \mathrm{kPa}$, Unite weight $\rho_{s}=1505.75\left(\mathrm{~kg} / \mathrm{m}^{3}\right)$, Rayleigh damping $\mathrm{D}=5 \%$, and Poisson's ratio, $v_{s}=0.49$. The default value embedded in ABAQUS software for the other parameters such as $\varepsilon$ and the out-of-roundness parameter is accepted because they have a negligible influence and the difficulties in their calibration without specific tests.

\subsection{Model criteria for the shaking table feature}

An elastoplastic model was achieved by using a flexible wall, soil, and piles. To prevent the model from collapsing or unacceptable deforming, Kevlar straps were employed to give the body rigidity. The majority of the material's characteristics and properties were obtained from the information presented in the literature (Meymand, 1998). The rubber membrane's elastic modulus was established as equivalent to that of the elastic modulus of the soil, which meant the lowest possible disturbance regarding responses from the soil as the value mentioned in (Meymand, 1998). In order to limit free vibration, the analysis utilized five percent Rayleigh damping. Table 2 presents the material properties and model parameters.

Table 2. The material properties and model parameters of the shaking table

\begin{tabular}{|c|c|c|c|c|c|c|}
\hline Material & model & $\begin{array}{c}(\rho) \\
\left(\mathrm{kg} / \mathrm{m}^{3}\right)\end{array}$ & $\begin{array}{c}(E) \\
(\mathrm{kPa})\end{array}$ & $(v)$ & $\begin{array}{c}\text { Yield } \\
\text { Stress } \\
(\mathrm{kPa})\end{array}$ & $\begin{array}{c}\text { Rayleigh } \\
\text { damping } \\
(\mathrm{D})\end{array}$ \\
\hline Pile & Elastoplastic model & 640.75 & $69.0 \mathrm{E}+6$ & 0.25 & 275.8 & $5 \%$ \\
\hline Ring & Rigid & - & - & - & - & $5 \%$ \\
\hline Membrane & Elastic model & 0 & 4200 & 0.25 & - & $5 \%$ \\
\hline
\end{tabular}




\subsection{Contact Modelling of soil structure interaction}

Simulation of SSI includes contact between two distinct features: the pile and the surrounding soil. Perfect modeling of this interaction is the most important factor of influence to deliver an accurate result, and this depends significantly on how the simulation implements assumptions and matches the realism during the modeling process. Normal, tangential, relative surface sliding and frictional shear stresses are the components of dynamic soil-pile interaction. In FEA the contact problem can be identified as a special case of discontinuous constraint, which can occur when loads transfer between contacting elements under interaction conditions. Once the two surfaces d0etach, the constraint is removed (the gap condition) and the slap condition takes its place during the return. The analysis can be managed by identifying the constraint consequently with and without contact conditions. ABAQUS offers two formulations for modeling such cases:

$>$ A small sliding formulation with limited sliding and arbitrary rotation of the contact surfaces is permitted.

$>$ A finite sliding formulation: separation and sliding of finite amplitude are allowed; arbitrary rotation of the contact surfaces can also arise.

In the situation of a laterally loaded pile, the relative surface motion falls into the category of 'small sliding'. To model the normal behavior, the option 'hard contact' is chosen as a contact property, which defines the pressure-clearance relation in the simulation of contact surfaces. By choosing the context 'allow separation after contact' once the value of the contact pressure becomes zero or less, the contact constraint will be removed. Surfaces in contact often transmit normal and shear forces along their contact interface. The Coulomb friction model defines the interaction relation of the contacting constraint surfaces, which is supported by ABAQUS. Two approaches are embedded in ABAQUS in order to set the basic Coulomb friction model. In this study, the method which identifies the static and kinematic friction coefficients directly and characterizes the exponential decay between the static value and kinematic value has been adopted. In conclusion, normal and tangential behavior are adopted in this study. Normal behavior allows the pressure to transmit between soil and pile while both surfaces are in contact with each other and this type of behavior will allow the soil to separate from the pile if the contact pressure reduces to zero. Tangential behavior enables shear stress (shear drag) to transfer between soil and pile surface as shown in Figure 4.

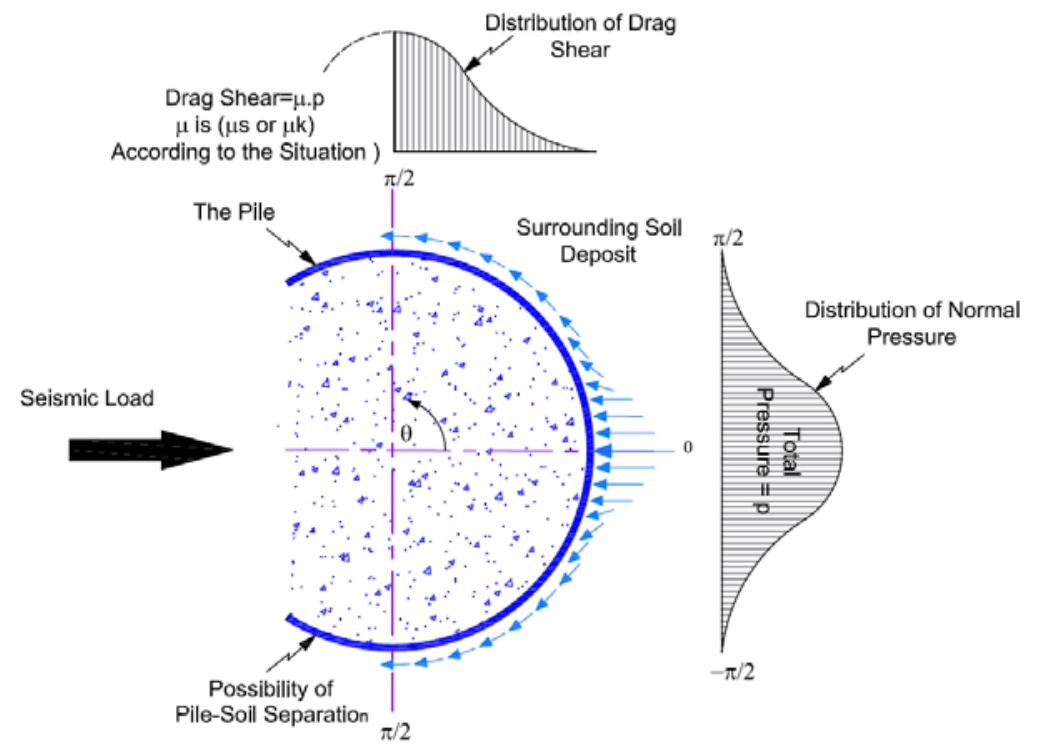

Figure 4. Soil-pile interaction model

\subsection{Results and discussion}


The design of the shaking table tests ensured that each of the test arrangements facilitated contrasting conditions of two or even up to five structural modes. Thus, by transferring the physical test to an accurate numerical analysis comparison for these modes can also be achieved. Figure 5 illustrates the pile head accelerometer time histories and acceleration amplitude as a function of frequency, i.e. fast Fourier transforms (FFTs) of a solitary pile set model that included five percent spectra damped response results for both physical and numerical simulation tests for the piles [P_1, P_2, P_3, P_4] and corresponding pile head masses equivalent to $72.60 \mathrm{~kg}, 45.36 \mathrm{~kg}, 11.35 \mathrm{~kg}$ and $3.0 \mathrm{~kg}$, respectively. Which are given as the material density of the superstructures. On the other hand, Figure 6 compares the values of the free field accelerometer time histories and (FFTs) between the physical and numerical simulation tests. The flexible wall barrel shaking table test validates the results computed. In order to perform the analysis in the frequency domain and achieve a profound understanding of the vibration profile of the results, which is difficult in the time domain, the pile head acceleration and free-field acceleration time histories have been transferred to (FFTs) to provide results for acceleration as a function of frequency by using a MATLAB script.

The results in Figure 5 showed that the acceleration amplitude of the simulation increased dramatically when compared to input motion and it has higher magnitude after the peak acceleration. Moreover, the influence of the superstructural inertial forces for P_1in the numerical model can be seen to be very similar to that in the physical model. Whereas, with the decreasing of pile head mass values for P2, P3, and P4 the impact of the superstructural inertial force decreased and consequently the difference between the results of the simulation and physical test increased.
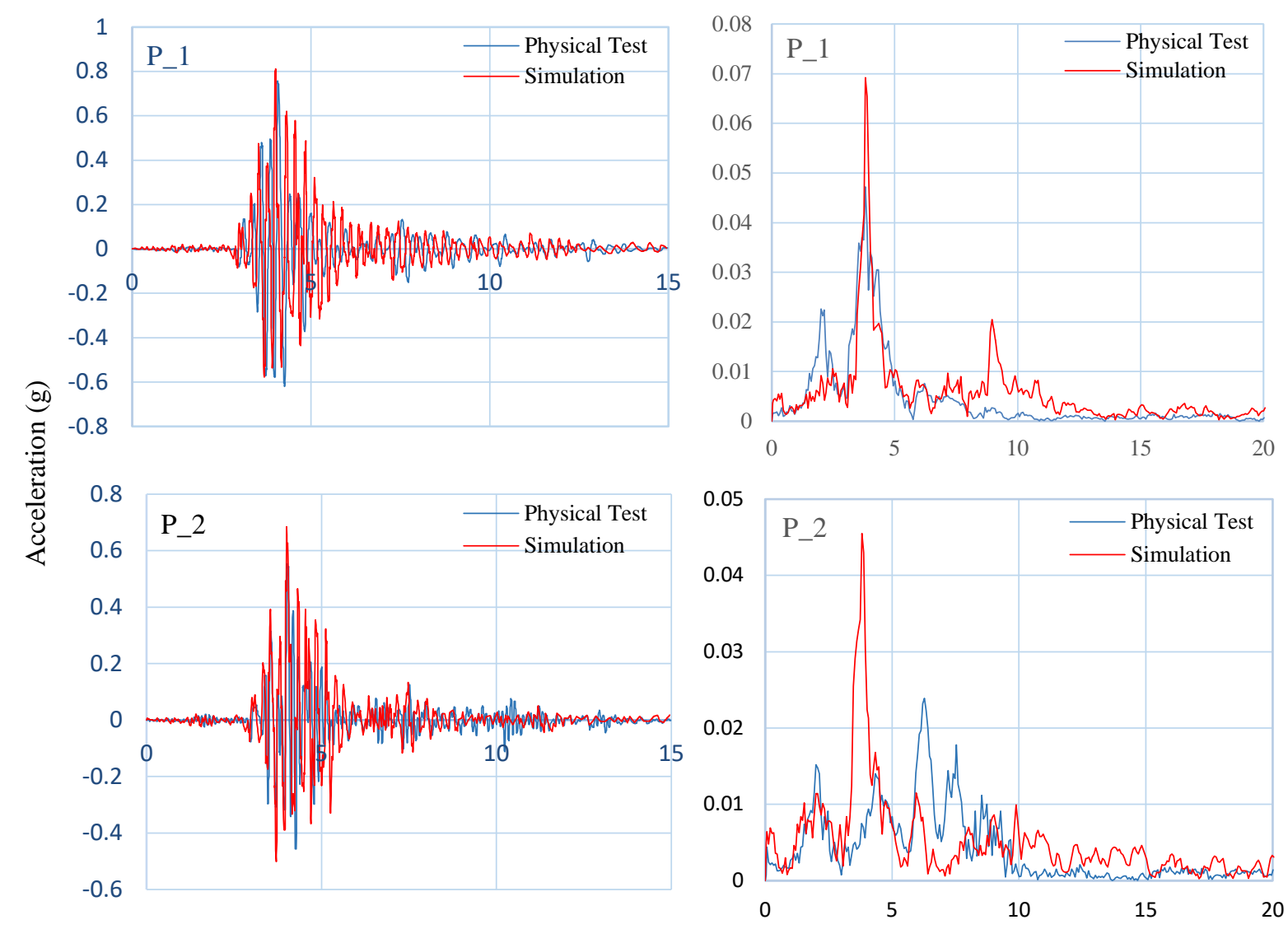

Time (Sec)

Frequency (HZ) 


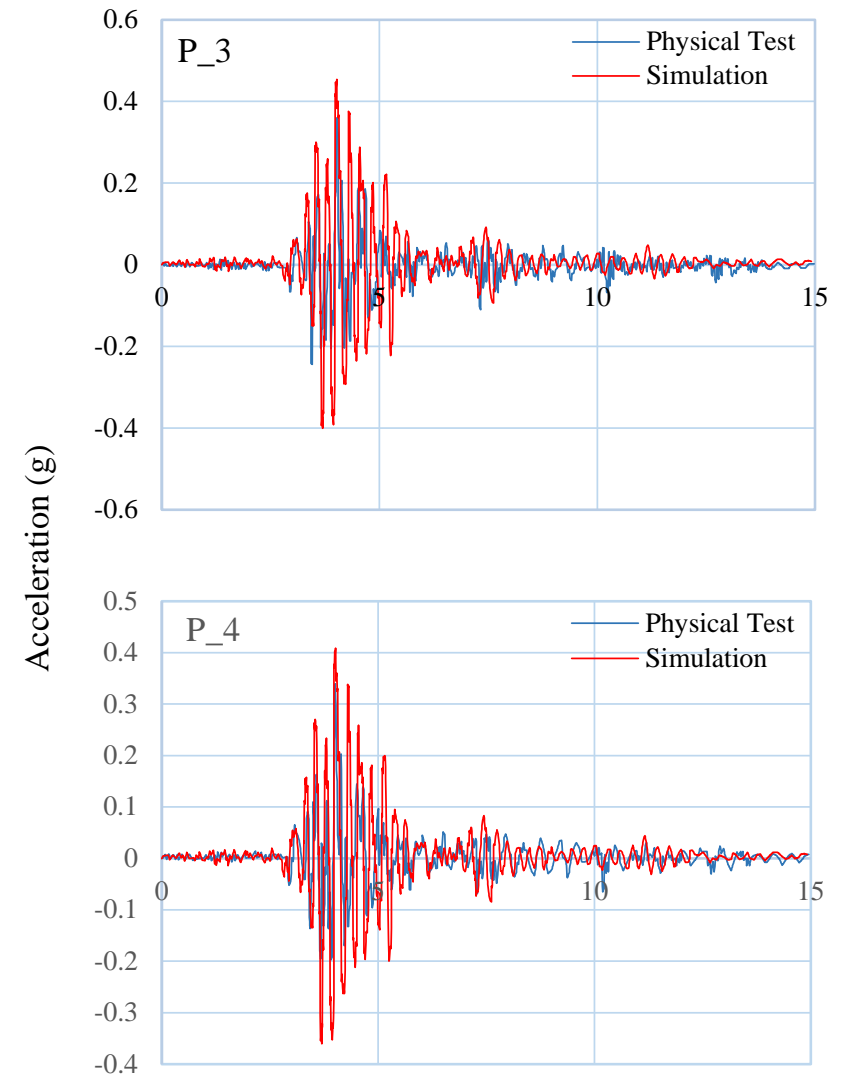

Time (Sec)
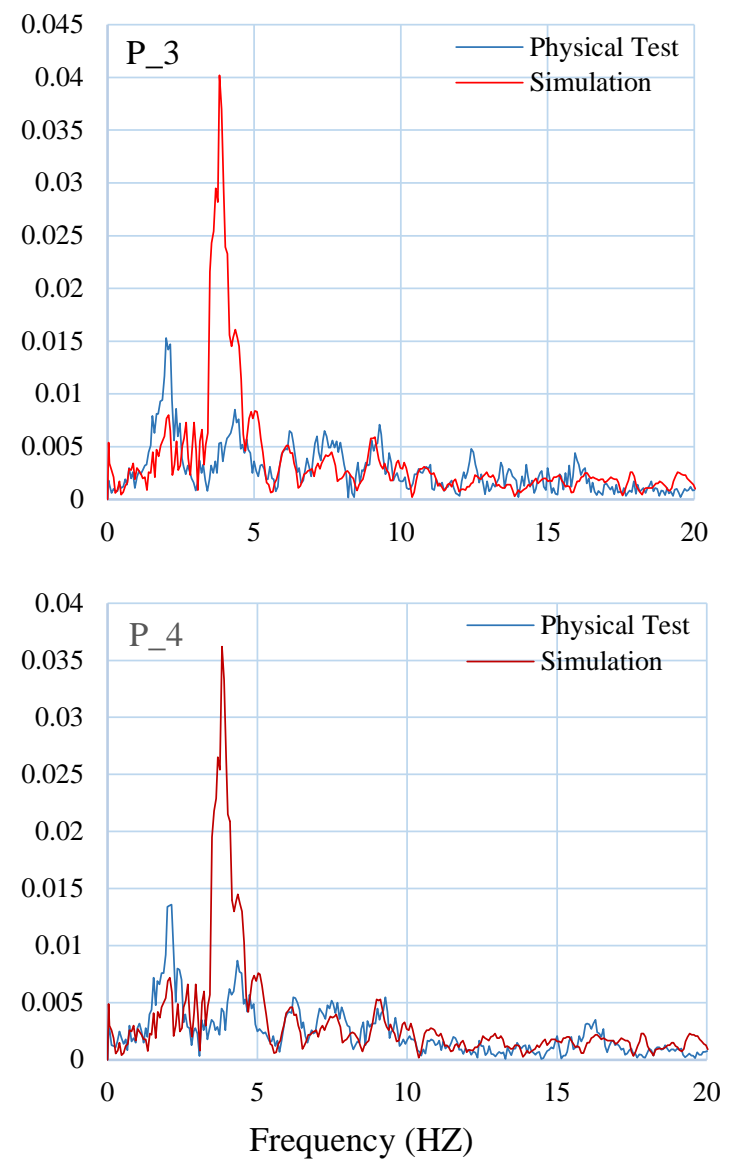

Figure 5. Pile Head Accelerometer Time Histories and FFTs

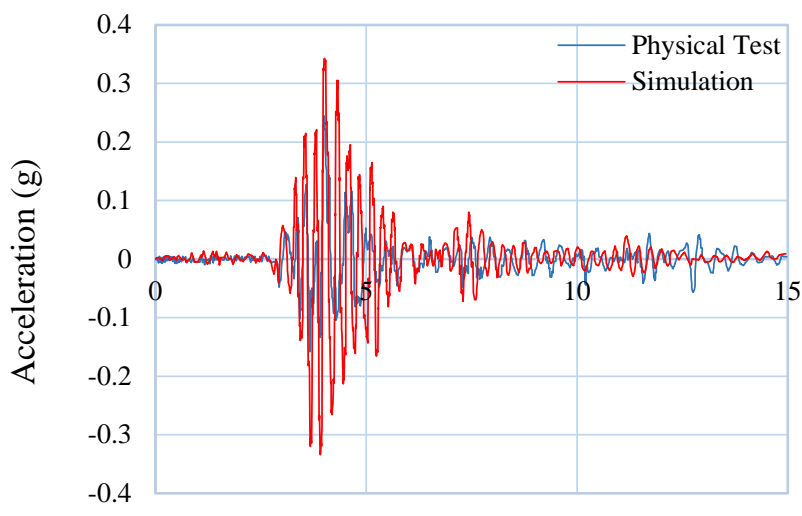

Time (Sec)

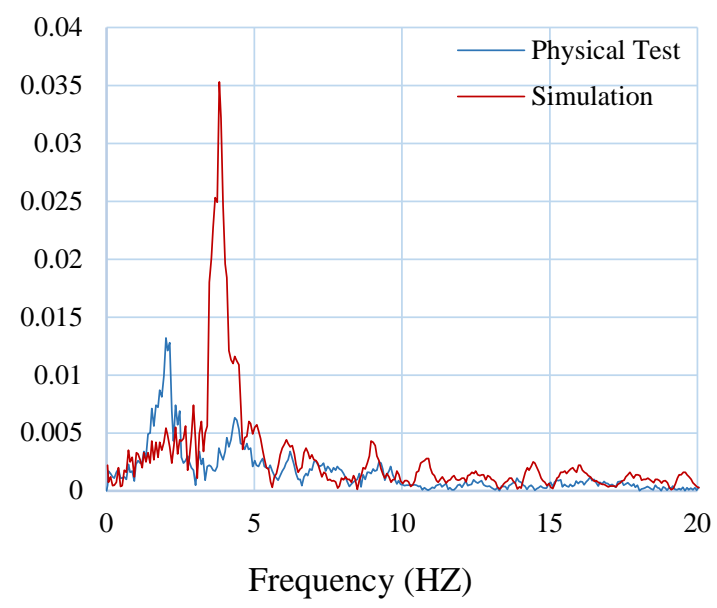

Frequency (HZ)

Figure 6. Free Field Accelerometer Time Histories and FFTs

The numerical model subjected to the YBI90 motion with a PGA of $0.20 \mathrm{~g}$, which resulting in a free-field PGA of $0.3427 \mathrm{~g}$ and pile head acceleration ranging between $0.4287 \mathrm{~g}$ for P_4 to $0.8117 \mathrm{~g}$ for $\mathrm{P} \_1$. Table 3 shows the comparison between the results for the reference case and those computed by numerical simulation; it is evident that the results of the simulation have a higher amplitude than those for the physical test. The relative change in results were then calculated by using the formula in equation 9:

Relative change $_{\left(\text {Acce.numerical, } \text { Acce. }_{\text {test }}\right)}=\frac{\text { Acce.numerical }_{\text {- Acce.test }}}{\text { Acce.test }}$ 
Table 3. Maximum piles head acceleration and PGA values

\begin{tabular}{|c|c|c|c|}
\hline \multirow{2}{*}{ Element. } & Physical Model & Numerical Model & Relative change in \\
\cline { 2 - 3 } & Acceleration (g) & Acceleration (g) & $7 \%$ \\
\hline Pile-1 & 0.7580 & 0.8117 & $23.3 \%$ \\
\hline Pile-2 & 0.5544 & 0.6845 & $25.8 \%$ \\
\hline Pile-3 & 0.3610 & 0.4541 & $26.1 \%$ \\
\hline Pile-4 & 0.3400 & 0.4287 & $52.4 \%$ \\
\hline Free-field & 0.2248 & 0.3427 & \\
\hline
\end{tabular}

As can be concluded from Table 3 the relative change in acceleration, which is indicated by the difference between the numerical analysis and the reference case has the highest value for the free-field; this value tends to decrease when the pile head weight increases. These values range between $7 \%$ and $52.4 \%$. Note the excellent correlation between the simulation and physical test result for the pile of maximum pile head mass, i.e., P_1. Whereas same as in the physical test a substantial similarity between simulations results of the P_3 and P_4 can be seen. A significant difference in free field PGA values between the simulation and reference case reach to $52 \%$. On the other hand, in order to achieve an explicit comparison between these two types of simulation regarding the energy content of the vibration profile, the destructive capability of the vibration, and taking into account the time history of the waveform. The rootmean-square values (RMS) for both types of simulation obtained by using a MATLAB script, as shown in Figure 7, which is confirmed in the aforementioned discussion of the results.

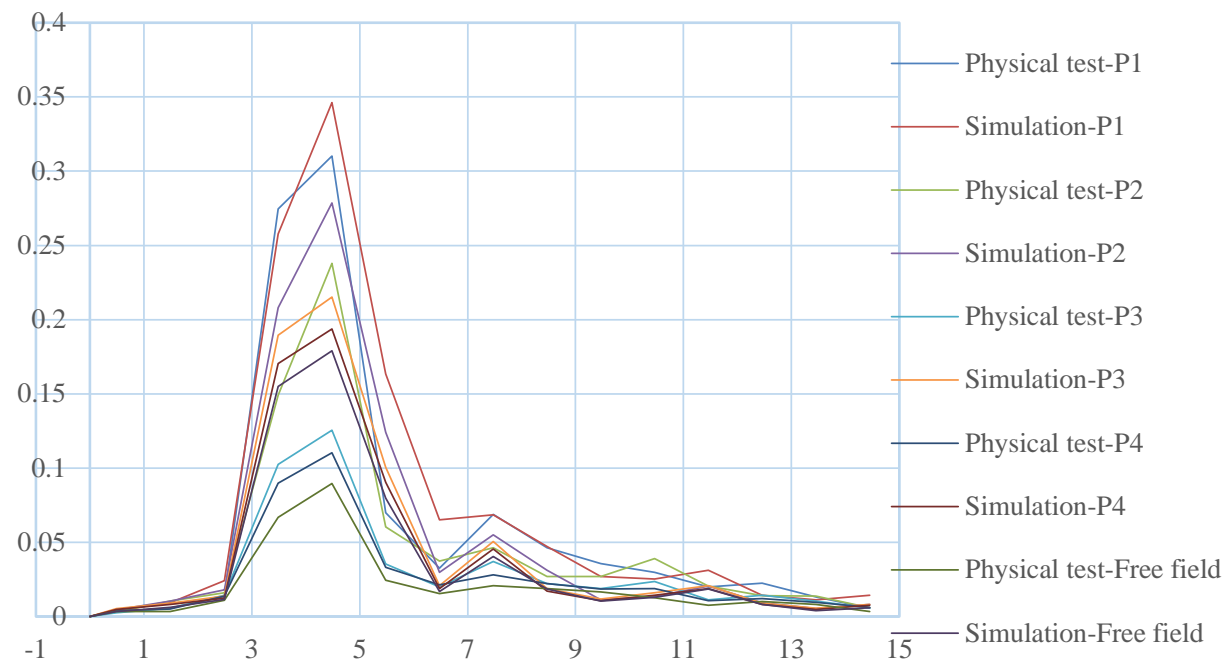

Figure 7. Root-Mean- Square (RMS)

This differentiation between the results of the physical and numerical model may be for the following reasons;

Firstly, several soil parameters are not mentioned in the reference case. Thus these parameters are computed from available information. Secondly, fly ash was added to the soil in the physical test and, therefore, the soil in the numerical model is potentially softer, which results in a larger gap formation. Lastly, as this study is part of a larger project, the soil's constitutive relationship and the elastoplastic response is simulated by the Extended Mohr-Coulomb criteria as a first option - which is suitable for a monotonic loading simulation (Maoguang \& Wang, 2009); therefore large errors may be produced in the case of dynamic loading, including during events like earthquakes. That can be seen clearly by looking at the difference between the free fields PGA results for both tests due to the dominant of soil failure criteria on model behavior 
in the numerical analysis. The gap-slap mechanism was detected in this simulation, and two observations were noted. Firstly, due to the creation of the gap, the unconfined length of the pile was increased and, thus, the pile obtained more area to drift horizontally; consequently, free vibration could take place after the shaking phase; a permanent gap between the pile and soil was also perceived. On the other hand, when the gap appears, contact between the soil and pile is removed causing a reduction in pile-skin resistance and the overall pile capacity also decreases. These two reasons, namely the free vibration and decrease in the skin-pile friction resistance, lead to an adverse influence on a superstructure and pile system particularly for a pile system supporting high head masses such as high-rise buildings.

\subsection{Conclusions}

- The use of a 3D FEA within the main target of the study for which a transformation of physical shaking table test to numerical test has been demonstrated. This has shown that a completely accurate numerical test can be performed by following an advance FEA procedure and, consequently, a new path for future research can be opened up for researchers who want to validate their model.

- A good correlation was seen between the simulations' results and the Meymand (1998) test.

- The Extended Mohr-Coulomb criteria were used to simulate the constitutive relationships of the soil as several parameters were not precisely identified as part of the physical testing. The results did not predict an exact fit as the Extended MohrCoulomb criteria were employed for earthquakes events, and could result in considerable errors.

- A majority of the SSPSI modes can be seen, for instance, the gap-slap mechanism, as well as the inertial forces of the superstructure and the kinematic soil-to-pile force. The period and the acceleration of the superstructure are increased by the gap-slap mechanism, which generates a free vibration that will induce a reduction in the capacity of the pile.

- The pile with high head structures will experience a greater gap-slap mechanism, causing a negative influence on superstructure and pile behaviour and this can be imposed especially for a high-rise building; for those with a lower head weight, the kinematic forces exposed by the soil significantly influence the pile.

- By using data from the physical test, the creation of 3D FEA through ABAQUS was possible so that a physical-to-numerical test transfer can take place. The material properties and soil-parameter properties must first be established accurately, and a relevant and appropriate soil failure criteria must also be carefully identified.

\section{References}

1. (PEER), T. P. E. E. R. C., 2008. PEER Ground Motion Database - PEER Center. [Online]

Available at: https://ngawest2.berkeley.edu/users/sign_in?unauthenticated=true [Accessed 6 Jan 2018].

2. ABAQUS, 2016. Abaqus Analysis User's Manual, Johnston, USA: Dassault Systèmes.

3. Badrakia, P., 2016. Estimation of Shear Wave Velocity Using Correlations. International Journal of Innovative Research in Science, Engineering and Technology, 5(6), pp. 10574-10580.

4. Bezgin, Ö., (2010). An Insight into the Theoretical Background of: Soil Structure 
Interaction Analysis of Deep Foundations. The Soil Mechanics and Foundations Division, ASCE, Volume 86.

5. Chen , W. F. \& Zhang , H., 1988. Plasticity for structural engineers. New York: Springer-Verlag .

6. Clough, R. W. \& Penzien , J., (2015). Dynamics of Structures. 2nd Edition ed. New York: McGraw-Hill.

7. Guin, J. \& Banerjee, P. K., 1998. Coupled soil-pile-structure interaction analysis under seismic excitation. ASCE library.org by Florida International University.

8. Kline, S. J., 1986. Similitude and Approximation Theory. New Yourk: SpringerVerlag.

9. Leoni, M., 2005. Implementation and use of constitutive models in geomechanics: analysis of shallow footings on sand.. Parma: University of Parma,University of Bologna,University of Brescia,University of Ferrara.

10. Malhotra, S., 2010. Seismic Soil-Pile-Structure Interaction: Analytical Models.

11. Maoguang, Y. \& Wang, Y.-Y., 2009. Soil-Structure Interaction of High-rise Building Resting on Soft Soil. EJGE, 13(Bund. D ).

12. Maoguang, Y. \& Wang, Y.-Y., 2009. Soil-Structure Interaction of High-rise Building Resting on Soft Soil. EJGE.

13. Menetrey, p. \& Willam, K. J., 1995. Triaxial failure criterion for concrete and its generalization. ACI Structural Journal, Volume 92, pp. 311-318.

14. Meymand, P. J., 1998. Shaking table scale model tests of nonlinear soil-pilesuperstructure interaction in soft clay. California: University of California, Berkeley.

15. Muir Wood, D., 2004. Geotechnical Modelling. UK ed. ed. London, United Kingdom: Taylor \& Francis Ltd.

16. Mylonakis, G. \& Gazetas, G., 2000. Seismic soil-structure interaction: beneficial or detrimental?. Journal of Earthquake Engineering, Vol. 4(No. 3), pp. 277-301.

17. Phanikanth1, V. S., Deepankar , C. \& Reddy, G. R., 2015. Behavior of single pile in liquefied deposits during earthquakes. ASCE library.org by Florida International University.

18. Phanikanth, V. S., Choudury, D. \& Gudheti, R. R., 2013. Behavior of Single Pile in Liquefied Deposits during Earthquakes. July/August, 13(4), pp. 454-462.

19. Zienkiewicz, O. \& Taylor , R., 2000. The Finite Element Method. 5th ed. Berkeley ,California: Woburn. 